\title{
Heidegger y el pensamiento universal
}

\section{Heidegger y los grandes clásicos}

Martin Heidegger (1889-1976) es sin duda el filósofo más original que ha dado Alemania en el siglo XX, y por su vinculación a la «Existenzphilosophie» también uno de los teóricos más representativos de nuestro tiempo, pero su sistema de ideas es inseparable de las corrientes centrales del pensamiento universal, desde los presocráticos y la filosofía medieval al subjetivismo moderno y a las corrientes irracionales del siglo XIX.

Esta estrecha vinculación a la «philosophia perennis» es también visible allí donde Heidegger disiente de los grandes maestros del pensamiento universal —que es la regla-y opone a ellos sus propias tesis. Aunque él subrayará (con razón) la independencia de su concepción del mundo y el carácter personal y solitario de su filosofía (lo que también es cierto) es innegable que sus posiciones fundamentales son replanteamientos, reinterpretaciones o reconstrucciones de actitudes ideativas anteriores a él, lo que explica que Jaspers haya podido decir que Heidegger «expresa viejas verdades en un lenguaje original», añadiendo de todos modos que lo hace «de manera insuficiente y torcida» 1 .

En su famoso diálogo con el profesor japonés Tezuka (1953-1954), el propio Heidegger dirá: «Para nosotros, hombres de hoy, puede convertirse en necesidad que preparemos tales diálogos, con el objeto de interpretar de modo propio a los pensadores antiguos» ${ }^{2}$. Éste es, en efecto, el punto de partida de su obra.

Como ocurre con todos los grandes sistemas de filosofía, el de Heidegger no es sólo la exposición de las propias ideas, sino, a la vez, la verificación de toda la herencia filosófica de la humanidad, sea en sentido crítico o afirmati-

1. Karl JASPERs, Notizen zu Martin Heidegger, p. 101, Munich 1978.

2. Martin Heidegger, Unterwegs zur Sprache, p. 124, Pfullingen 1959. 
vo. Por eso Heidegger dirá: «En la primera página de «Ser y tiempo» se habla expresamente de «repetir» (Widerholen). Esto no significa el despliegue uniforme de lo eternamente idéntico (immer Gleichen) sino: coger, recolectar, recoger lo que se oculta en lo viejo' ${ }^{3}$.

Heidegger parte casi siempre -explícita o implícitamente- de los viejos filósofos, no para asumir miméticamente sus enseñanzas, sino para interpretarlas bajo una nueva luz y sacar sus propias conclusiones. La característica central de la filosofía heideggeriana es precisamente ésta: la de constituir una síntesis más o menos lograda entre el pensamiento clásico y el pensamiento moderno, entre lo arcaico y lo nuevo.

Ahora bien, esta síntesis no debe ser entendida como una progresión o culminación de los grandes sistemas de filosofía, es decir, como una aportación complementaria a ellos, sino más bien como una ruptura cualitativa con lo aparentemente último y definitivo. De ahí que Heidegger caracterice su filosofía no como un paso hacia adelante, sino como un «paso atrás»: «Para nosotros, el carácter del diálogo con la historia del pensamiento no es la superación (Aufhebung), sino el paso atrás» ${ }^{4}$.

Con esta afirmación - aparentemente paradójica- Heidegger no hace más que expresar que toda la metafísica occidental —desde Platón a Husserl- no es más que un tremendo proceso de desviación, y que, por tanto, la labor propia de la filosofía - o del «pensar», como él especifica- ${ }^{5}$ es la de regresar a los orígenes del pensamiento griego, no para copiarlo, sino para replantearse de nuevo el problema del ser, un problema que, lejos de haber sido esclarecido por la filosofía clásica, sigue siendo una incógnita. De ahí esa tremenda afirmación: «La misión del pensamiento actual es pensar lo que pensaron los griegos de manera todavía más griega para comprender a los griegos mejor de lo que ellos se comprendieron a sí mismos» ${ }^{6}$. A diferencia de Hegel, dirá Heidegger, «nosotros buscamos la fuerza no en lo ya pensado (Gedachten), sino en algo impensado (Ungedachten), de lo cual lo pensado recibe su espacio esencial» ${ }^{7}$.

$\mathrm{Su}$ labor investigacional es una confrontación continua con los grandes representantes del pensamiento universal, hasta tal punto que sobre todo tras la publicación de «Ser y tiempo», su filosofía se convierte en hermenéutica crítica de la filosofía tradicional. La originalidad de Heidegger y lo que de hecho

3. loid., p. 131 .

4. HEIDEGger, Identität und Differenz, p. 45, Pfullingen 1957.

5. Véase Zur Sache des Denkens, Tubinga 1969.

6. HEIDEGGER, Unterwegs zur Sprache, 1.c., p. 134.

7. HeIDEgGer, Identität und Differenz, l.c., p. 44. 
le diferencia de los demás representantes del pensamiento existencial radica en gran parte en haber sabido redescubrir los elementos genéticos y a la vez olvidados de la filosofía antigua, frente a la que adopta muy pronto una actitud crítica y, a veces, demoledora.

Porque otro de los rasgos constitutivos de la filosofía heideggeriana es su dimensión polémica, su tendencia (abierta o solapada) a menospreciar las filosofías ajenas a la suya, a situarse en un plano de superioridad frente a los demás pensadores, un rasgo que Jaspers lamentará una y otra vez, hablando del carácter «coactivo, polémico, dominante y pretencioso» de la filosofía de Heidegger y comparando su conducta a la cólera de Júpiter: «Heidegger lanza sus pretensiones de poder como Júpiter sus rayos desde las nubes. Pero son sólo humo y juegos artificiales» ${ }^{8}$.

Sorprende, en efecto, ver cómo ya el joven Heidegger, en sus primeras disertaciones académicas, pone en entredicho la obra de los grandes padres de la filosofía -empezando por Platón y Aristóteles-y adopta una actitud de clara superioridad frente a ellos, como si se tratara de aprendices de brujo y él fuera el espíritu destinado a resolver todos los misterios de la filosofía, actitud que mantendrá hasta el fin de sus días, a pesar del tono formalmente humilde que a veces adopta. ¡Qué contraste con la modestia de un Kant! Cuando todavía está en los pañales de la fenomenología husserliana, cuando todavía se nutre de su mentor filosófico número uno, Heidegger se presenta ya como una especie de mesías intelectual cuya misión es la de salvar la tradición filosófica universal del error a la que la han conducido sus predecesores.

Detrás de los interminables ejercicios de lógica formal a que se entrega el joven profesor, asoma no sólo su poderosa fuerza mental, sino también la soberbia del pensador que cree que él y únicamente él representa la nueva filosofía, el comienzo de una nueva era filosófica, cuando en realidad su sistema se revelará al final como una variante - todo lo original y profunda que se quiera- del pesimismo nihilista que encontramos ya en los comienzos del pensamiento universal, aunque uno de sus numerosos admiradores haya hablado nada menos que de su «optimismo ontológico» ${ }^{9}$.

Esta tendencia a la autoglorificación se reviste, en su fase madura de creación - la fase posterior a «Ser y tiempo» y a su identificación con el nacionalsocialismo hitleriano-, de humildad, pero de una humildad más formal que substancial, porque incluso cuando Heidegger parta del supuesto de

8. Karl JASPERS, 1.c., p. 47 y 92.

9. «Puesto que ya el término «Da-sein» significa la afortunada y bienhechora llegada del ser, aunque sea finito e insuficiente» (Max Múller, Existenzphilosophie, p. 57). 
que la filosofía no está en condiciones de penetrar en el misterio úlimo del ser - tampoco la suya - no renunciará a su idea fija de considerar que toda la filosofía anterior a él es un puro error.

\section{Kant, Hegel, Dilthey y el pensamiento místico}

Dentro de su actitud crítica global, sus ataques principales los destina a Hegel, a quien tacha de sofístico. Kant es también objeto constante de sus críticas, pero el tono que adopta frente a él es más respetuoso y matizado, quizá porque sabe lo que en el fondo le debe, que es mucho. Aunque reprochará al maestro de Königsberg no haber superado la tradición del cogito cartesiano, admite por lo menos que intentó seriamente encontrar la verdad, pero quedándose a medio camino. En cambio trata con absoluto desprecio a los neokantianos.

La filosofía heideggeriana representa, tanto por su punto de partida como por sus consecuencias finales, la negación más crasa de la filosofía kantiana, pero a pesar del antagonismo de ambos sistemas, Heidegger se mueve en la órbita del pensamiento de Kant, permanece atado al dualismo establecido por el filósofo de las «Críticas» entre fenómeno y númeno, entre apariencia y cosa en sí. La ontología fundamental de Heidegger lleva la impronta inequívoca de la «Crítica de la Razón Pura» de Kant, una influencia que el filósofo de los Bosques Negros recibe por partida doble: por medio del estudio directo de Kant y a través de la fenomenología husserliana, ella misma penetrada de kantianismo.

La filosofía kantiana parte del supuesto de que la cosa en sí o verdad última no puede ser aprehendida por el sujeto y que, por tanto, entre la conciencia y la verdad existe siempre un hiato insuperable. En el fondo, ésta es también la posición de Heidegger, con la sola diferencia de que el autor de «Ser y tiempo» transforma la dicotomía kantiana entre sujeto y objeto en el dualismo entre ser (Sein) y ser ahí o existencia (Dasein), un paso que Kierkegaard había dado ya frente a la filosofía hegeliana.

Los mismos esfuerzos que Kant lleva a cabo para demostrar que «das Ding an sich» (cosa en sí) es ininteligible para el cogito, los realiza Heidegger para convencernos de que su Dasein no está en condiciones de desentrañar su fundamento último. Ahorá bien: mientras Kant, fiel a la filosofía humanista de la ilustración superará dialécticamente la aporía entre conocimiento objetivo y subjetividad recurriendo a la noción de praxis - es decir, a la ética y a la razón práctica-, Heidegger, prisionero de la perspectiva pesimista de su tiempo, transforma la desorientación del Dasein en una categoría absoluta e irreversible. 
Heidegger no se liberará nunca del dualismo kantiano, y su intento de superar el «impasse» entre empirismo y trascendencia eligiendo la muerte como fin supremo del hombre, como su verdad más profunda y auténtica, no es más que un salto irracional en el vacío, un salto dado ya antes por Kierkegaard, aunque no eligiendo la nada, como Heidegger, sino la fe religiosa.

Recordemos aquí que el fin de la existencia humana no consistía para Kant en la teoría, puesto que ésta no puede satisfacer plenamente el afán cognoscitivo del sujeto, y por tanto, no puede darle la certidumbre epistemológica que éste necesitaría para poseer una visión segura e incuestionable del universo. Precisamente porque el hombre no está en condiciones de penetrar en los últimos arcanos de la creación a causa de los límites intrínsecos de la razón pura, no le queda otra opción que la de liberarse de este callejón sin salida eligiendo el camino de la conducta moral. Con esta actitud Kant se identifica con la gran tradición cristiano-humanista de Occidente, y es aquí donde Heidegger -insensible a los valores éticos - se separa de él para elegir la vía del irracionalismo.

Heidegger es también deudor profundo de Hegel, uno de los grandes filósofos clásicos a los que más encarnizadamente combatirá, siguiendo aquí también el ejemplo de Kierkegaard. Toda la estrategia heideggeriana de interpretar el Dasein como temporalidad o ser-en-el-tiempo es de origen hegeliano, aunque el concepto de historicidad lo asumirá Heidegger sobre todo a través de la mediación de Dilthey.

Ahora bien, mientras el concepto de «werden» o devenir juega en Hegel un papel ascendente, Heidegger lo convierte en regresión y descenso, en nihilismo y muerte. Es decir, entre ambos se produce una inversión axiológica: si Hegel ve en el futuro la culminación de la historia universal o realización del «Weltgeist» a través del espacio y el tiempo, Heidegger lo interpretará sobre todo como el despliegue del no-ser, como una manifestación de la «Unwahrheit» o error, como caída del ser o «Seinsverfall». Para decirlo con las palabras del italiano Chiodi: «Hegel concibe la historia como el orden necesario de la revelación del ser, Heidegger como el orden necesario de la no-revelación del ser» ${ }^{10}$.

Dilthey intenta superar la «razón pura» de Kant a través de la «razón histórica» y parte del concepto de historicidad como módulo fundamental para comprender el significado de cada respectiva época, que él interpreta como la expresión de un determinado «Lebensgefühl» o sentimiento vital, una posición que está ya perfectamente preconfigurada en el historicismo de Herder y

10. Pietro Chiod, L'Ultimo Heidegger, p. 42, Torino 1969. 
Hegel. Para Dilthey, la historia sólo puede ser comprendida por medio de una intuición subjetiva de cada respectiva fase histórica, nunca a través de las ciencias naturales. Esta visión historicista influenciará poderosamente a Heidegger, con la diferencia de que mientras Dilthey concibe el significado de los diversos estadios históricos como una manifestación objetiva, Heidegger parte de una perspectiva totalmente subjetivista y solipsista. Pero estas y otras divergencias no merman la afinidad que en aspectos fundamentales existe entre ambos pensadores, como De Waelhens subraya: «Dilthey fue el primero en anticipar la tesis de que las diversas impresiones (Erlebnisse) no son una serie de acontecimientos discontinuos y separables, sino un flujo, una unidad esencial. De todo esto va a surgir pronto esta idea típicamente heideggeriana: no, comprendemos más que lo que somos, y somos lo que comprendemos. Comprehensión del ser y ser son integrados en un mismo círculo, y entre ellos existe un intercambio continuo. Y por él mismo vemos justificada la tesis de que el conocimiento del hombre no es una facultad independiente de su existencia, sino que es una función de ésta»" ${ }^{11}$.

A pesar de su ateísmo fundamental, la obra de Heidegger está profundamente vinculada a la teología, la mística y la filosofía medievales, en las que se mueve con toda familiaridad, como demuestra su tesis doctoral sobre Duns Scoto, y de las que recibe poderosos impulsos no solamente formales. Antes de pasar al estudio de la filosofía «sensu stricto», Heidegger siguió cuatro cursos de teología y fue alumno de Carl Braig, profesor extraordinario de filosofía en la facultad de teología de Freiburgo, cuyo libro «Vom Sein. Abriss der Ontologie» (1896), le familiarizó con el pensamiento de Aquino, Suárez y la teología especulativa en general, también con el papel que dentro de esa disciplina jugó la filosofía de Hegel y de Schelling.

En este contexto debe señalarse la influencia ejercida sobre Heidegger por el maestro Eckhart, de quien por ejemplo asumiría el concepto clave de «Abgeschiedenheit» (separarse de los demás) como fuente de la verdad. No menos visible es el cordón umbilical que une la filosofía heideggeriana con la tradición de san Agustín y Pascal, ambos precursores del existencialismo cristiano de Kierkegaard y sus discípulos. San Agustín anticipa ya la filosofía existencial de los siglos XIX y XX al convertir la fe en vivencia personal, en biografía íntima, en vida interior, en «confessio». Lo mismo Pascal, cuyo tono sombrío reencontraremos, con otra terminología y en un contexto distinto, tanto en Kierkegaard como en el propio Heidegger. Las connotaciones pseudoreligiosas y sobre todo místicas y gnoseológicas de Heidegger explican entre

11. A. de WAELhens, La philosophie de Martin Heidegger, p. 326, cuarta edición, Lovaina 1955. 
otras cosas que a pesar de su ateísmo -más implícito que explícito-, su sistema de pensamiento será acogido con gran respeto y hasta veneración por importantes sectores creyentes, tanto católicos como protestantes, aunque no faltarán tampoco los pensadores religiosos que rechazarán su «Weltanschauung» como anticristiana, o aceptarán su metodología sin identificarse con sus tesis de fondo.

\section{Kierkegaard y Nietzsche}

Existe una tendencia muy extendida a considerar la «Existenzphilosophie» de Heidegger como una simple versión atea del existencialismo de Kierkegaard, interpretación que, a nuestro juicio, es demasiado sumaria para corresponder a la verdad. Si hubiera que mencionar a algún maestro de Heidegger, habría que citarse en primer lugar a Nietzsche, y no al pensador danés. Mientras Heidegger consideraba a Nietzsche como a uno de los grandes filósofos de la humanidad - de ahí la atención que dedica a su obra- negó a Kierkegaard la categoría de pensador, calificándole simplemente de «escritor religioso», epíteto que en Heidegger tenía siempre una connotación más bien peyorativa ${ }^{12}$. En «Ser y tiempo», Heidegger acusará a Kierkegaard de haber estado ontológicamente bajo la influencia de Hegel y de la filosofía antigua desde la perspectiva hegeliana ${ }^{13}$, lo que también es una afirmación claramente negativa.

Pero a pesar de la actitud distanciada que Heidegger adopta frente a Kierkegaard y de sus preferencias por Nietzsche, es a él a quien debe el planteamiento de la existencia como radical subjetividad, una subjetividad que en nombre de la verdad personal e interior se coloca frente al universalismo cristiano-humanista y abre la puerta al hiperindividualismo irracionalista de los últimos ciento cincuenta años. De Waelhens: «Nuestra tesis es, pues, la de que, con las reservas expuestas anteriormente, la concepción kierkegaardiana de la existencia es también la que sirve de base a la filosofía existencial de Heidegger» ${ }^{14}$. Común a ambos es la creencia de que el primer estadio del hombre es siempre el del error, y que es sólo a través de un proceso dialéctico de purificación (religiosa en Kierkegaard, noética en Heidegger) que el hombre supera su condición primaria de extravío para encontrarse a sí mismo. Más adelante

12. HeidegGer, Holzwege, p. 230, Francfort 1950.

13. Heidegger, Sein und Zeit, p. 235, undécima edición, Tubinga 1967.

14. De Waelhens, 1.c., p. 331. 
tendremos ocasión de comprobar el papel que el concepto de pecado y culpa juega en esta interpretación de lo real-inmediato como lo malo o erróneo.

Las afinidades de principio entre Kierkegaard y Heidegger no significan que la subjetividad de ambos sea una y la misma. Muy al contrario. Mientras Kierkegaard parte de la existencia concreta en su acepción más profunda y radical, Heidegger, a pesar de que temática y formalmente se ocupe también del Dasein o ser ahí, separa estrictamente su discurso filosófico de su vida personal, un rasgo objetivista que corresponde a la influencia ejercida sobre él por la «ciencia pura» de Husserl. De ahí que a pesar de su indudable originalidad y de sus ataques constantes al pensamiento científico, Heidegger permanezca adicto a la tradición de la filosofía profesoral y académica de su país, mientras que si algo caracteriza a Kierkegaard —como también a Nietzsche — será su desprecio por los filósofos de escuela. De Waelhens señala con razón: «El principal esfuerzo de Heidegger será ante todo el de elevar la doctrina de Kierkegaard al rango de una filosofía técnica»" ${ }^{15}$.

Más allá de sus diferencias formales y metodológicas, existe entre Kierkegaard y Heidegger el abismo de sus respectivas posiciones con respecto al problema de Dios. Mientras que el pensador danés ve en la fe religiosa la única actitud coherente frente al problema de la existencia humana o finita, Heidegger es en este punto discípulo de Nietzsche, de quien asume su «Dios ha muerto», aunque él, por razones convencionales y por su inclinación a la ambigüedad, intentará a menudo relativizar o poner en suspenso su ateísmo fundamental. De ahí que Martin Buber, en su profunda exégesis sobre Kierkegaard y Heidegger, ponga el dedo en la llaga al decir: «Pero el hombre Heidegger, aunque parta de Kierkegaard, significa un gran paso decisivo hacia el abismo donde comienza la nada» ${ }^{16}$.

A pesar de este antagonismo esencial entre religiosidad y ateísmo, entre fe y nihilismo, Heidegger comparte plenamente la hostilidad de Kierkegaard por el puro conocimiento teórico, por el idealismo; asimismo, comparte el desprecio de Kierkegaard por la vida colectiva y por las tradiciones democráticas, y su «Man» o ser-en-el-mundo recuerda claramente el concepto kierkegaardiano de «muchedumbre», «Menge» o «Plebs». Ambos buscan la salvación en el interior de su alma, en la radical soledad del yo, con la diferencia - una diferencia básica - de que mientras Kierkegaard superará este solipsismo a través de su afirmación de Dios, Heidegger no lo trascenderá nunca, permaneciendo pricionero perpetuo de su concepción nihilista de la existencia, buscando en su

15. Ibid., p. 330 .

16. Martin Buber, Das Problem des Menschen, p. 126, Heidelberg 1982. 
soledad de los Bosques Negros una iluminación ontológica que no se le revelará nunca.

La influencia que Kierkegaard y Nietzsche ejercieron sobre Heidegger es perfectamente localizable y delimitable: el primero juega un papel importante en la gestación de «Ser y tiempo» ${ }^{17}$, mientras que el segundo adquirirá prioridad tras la publicación de este libro, a partir de 1930. Pero al margen de esta periodización de la influencia de ambos, el pensamiento heideggeriano es inseparable de las enseñanzas de Kierkegaard y Nietzsche, y como ha dicho Leo Gabriel «en la filosofía de Heidegger se entrecruzan de manera única el pensamiento existencial de Kierkegaard y el de Nietzsche» ${ }^{18}$. Que al final, la filosofía heideggeriana diferirá totalmente de la de ambos, no anula la deuda contraída con ellos.

La transición de Kierkegaard a Nietzsche marca cronológicamente el paso del ambiente desintegrado y caótico de la República de Weimar y del período de entreguerras en general al ascenso del fascismo europeo y del nacionalsocialismo en particular; es decir, constituye el paso de la desesperación y del ser-para-la-muerte a la voluntad de poder y al superhombre nietzschiano ${ }^{19}$. Pero a pesar de su veneración por Nietzsche, Heidegger no aceptará como definitivo su pensamiento, del que finalmente se distanciará.

Heidegger permanece en la tradición del ateísmo germano, pero en vez de elegir el ateísmo humanista de Feuerbach o el ateísmo revolucionario de Marx, sigue las huellas del ateísmo pesimista de Schopenhauer e irracionalista de Nietzsche, nombres a los que habría de añadirse el de Max Stirner, otro de los primeros grandes exponentes del ateísmo alemán.

Heidegger comparte la nostalgia del ateísmo irracionalista por la afirmación de un yo liberado de toda regla de conducta moral o religiosa, actitud que vemos reflejada sobre todo en el «Einziger» (Único) de Stirner y en el «Ubermensch» (superhombre) nietzschiano. Sólo los planteamientos y la terminología son distintos, así como el contexto de la época; pero las consecuencias son muy parecidas: la vida carece de sentido, y por eso hay que superar este hecho fundamental inventando una tabla de valores que rompa con toda la tradición

17. Sobre todo a través de Karl Jaspers, que fue el primero en ocuparse a fondo del pensador danés en Alemania, tanto en sus libros como en su cátedra, y que, por ello, debe ser considerado como el verdadero fundador de la «Existenzphilosophie» germánica.

18. Leo GABRIEL, Existenzphilosophie, p. 212, Viena 1968.

19. Señalemos aquí de todos modos que Nietzsche tiene muy poco que ver con la bestialidad nazi y que si Hitler y demás líderes nacionalsocialistas utilizaron su nombre para sus campañas de propaganda, fue falsificando esencialmente su doctrina, en la que no se encuentra ninguna afirmación que pueda justificar el racismo teutónico. Su opinión sobre los alemanes era, al contrario, abiertamente peyorativa. 
espiritual, moral e intelectual de la humanidad. Nietzsche resumirá esta actitud en la fórmula descarnada de «freie Mächte, ohne Ethik!» (¡Libres poderes, sin ética!). Heidegger, menos ingenuo y más ligado a la filosofía profesional, negará la metafísica a partir de Platón y se pronunciará al final por un oscurantismo quietista basado en la adoración arcaizante del «Sein» original de los presocráticos. Pero ambos parten del supuesto de que Dios ha muerto y de que la única salida es una «transmutación de todos los valores».

Más tarde, ya en pleno III Reich, y, sobre todo, tras el hundimiento del hitlerismo, la influencia de Nietzsche dejará paso otra vez a la dimensión mística, pero no ligada ya necesariamente a la experiencia religiosa de Kierkegaard, sino originada por otros motivos.

\section{Husserl y la fenomenología}

Técnicamente, el punto de partida de Heidegger es Husserl, su maestro en Freiburgo, a quien en 1929 sustituirá como rector de la Facultad de filosofía. Heidegger entró en contacto con el pensamiento de su futuro maestro mucho antes de conocerle personalmente, concretamente a través de la lectura de las «Investigaciones lógicas», que leyó siendo estudiante. Pero fue sobre todo a partir de 1916, cuando Husserl llegó a Freiburgo como sucesor de Rickert que Heidegger tuvo ocasión de familiarizarse a fondo con la filosofía de su maestro, de quien a partir de 1919 fue asistente de cátedra.

Heidegger es inconcebible sin la labor preparatoria de la fenomenología husserliana, que él transformará en ontología fundamental. Lo que Heidegger llama el «pensamiento esencial» está en la línea intuitiva de la «Wesenschau» o visión esencial de Husserl. Como éste, rechaza el pensamiento científico como algo subalterno y parte de la puesta en duda de todo lo existente como principio del verdadero conocimiento. La «epoche» husserliana es también la actitud fundamental de Heidegger. Pero mientras Husserl se mueve todavía en la tradición filosófica clásica, en el neokantianismo y el humanismo liberal, en Descartes y Platón, Heidegger representa el irracionalismo abierto, sin ningún contrapeso racional-humanista. Como dice Adorno, «su discurso sobre el ser presupone la doctrina husserliana de la intuición categorial o visión de la esencia... Pero Heidegger rechaza el momento racional que Husserl preservó, y acercándose más bien a Bergson, practica implícitamente un procedimiento que sacrifica la relación con el concepto discursivo» ${ }^{20}$.

20. Theodor W. AdoRno, Negative Dialektik, en «Gesammelte Schriften», tomo 6, p. 77, Francfort 1973. 
La influencia de Husserl es muy acusada en la primera fase creadora de Heidegger, en la que éste se mueve casi enteramente en el ámbito terminológico e investigacional de su maestro y está todavía muy lejos de los juegos de palabras y del misticismo semántico posterior. Julius Kraft: «Husserl utilizó con frecuencia nuevas construcciones semánticas, pero con la intención de alcanzar la máxima claridad..., mientras el estilo típico de Heidegger se caracteriza precisamente por la desaparición de todos los contornos precisos» ${ }^{21}$.

Pero incluso en su fase husserliana, Heidegger fue todo lo contrario de un epígono de su maestro, como demuestran los reparos críticos que opuso a las «Investigaciones lógicas» mientras explicaba esta obra de Husserl a sus alumnos de Marburgo, en el invierno de 1925-1926. Ya antes de publicar «Ser y tiempo», el tono de Heidegger con respecto a Husserl no es siempre el del alumno con relación al maestro, sino que a ratos parece más bien que sea Heidegger el maestro y Husserl el alumno.

\section{El trasfondo histórico-ideológico}

El tema de Heidegger es la muerte, aunque la apología de la nada sea hecha en nombre de la autenticidad ontológica y pretenda superar precisamente el supuesto nihilismo de la filosofía clásica a partir de Platón y Aristóteles. Es justo, pues, lo que Emmanuel Mounier dice: «El caballero de la muerte de Durero, símbolo preferido de Nietzsche, es la imagen central de la antropología heideggeriana» ${ }^{22}$.

El pensamiento de Heidegger representa, en sus concavidades más profundas, un hipersubjetivismo radical y sombrío que ha roto con todas las ilusiones del mito burgués del progreso y del individuo libre y que concibe al hombre como absurdo, como nada y ser-para-la-muerte. De ahí sus ataques a Descartes, en el que ve «el comienzo de la culminación de la metafísica occidental» ${ }^{23}$, lo que en el lenguaje heideggeriano significa la culminación del nihilismo y de la alienación ontológica.

Husserl -y con él todo el subjetivismo liberal-burgués anterior a 1914teoriza todavía en un mundo externo intacto, en el que las estructuras morales y económico-sociales conservan su plena vigencia, en el que el capitalismo se encuentra en una fase de expansión y desarrollo, mientras que Heidegger filo-

-21. Julius Kraft, Von Husserl zu Heidegger, p. 84, Francfort 1957.

22. Emmanuel Mounier, Introduction aux Existencialismes, p. 61, Paris 1965.

23. HeIDEGGER, Holzwege, 1.c., p. 91. 
sofa en un momento histórico en el que la estabilidad y el esplendor burgueses han sufrido la tremenda conmoción de la primera guerra mundial.

Heidegger no acepta el mundo agonizante de la burguesía de postguerra no sólo por la vulgaridad de sus valores, sino también porque en el epicentro de este mundo está Alemania derrotada y humillada por el Tratado de Versalles. Los dicterios demagógicos de Hitler contra la democracia liberal de la República de Weimar tienen el mismo origen emocional que los lamentos metafísicos de Heidegger sobre el dominio del «Man» y su mundo impersonal e inauténtico. En este sentido no es exagerado decir que la filosofía de Heidegger es, en una de sus motivaciones primarias, una filosofía del resentimiento, rasgo que si primero aparece como resignación y miedo (en «Ser y tiempo», en «¿Qué es metafísica?»), se transformará luego, a partir del tercer Reich (con el que Heidegger se identifica un tiempo), en revanchismo y hostilidad contra las dos fuerzas históricas que amenazan a Alemania: el capitalismo yanqui y el comunismo ruso.

Derrotada Alemania de nuevo en los campos de batalla, Heidegger volverá a la resignación y al quietismo místico, pero sin abandonar nunca su hostilidad de fondo contra el mundo burgués-democrático y su antípoda el mundo comunista, en los que ve dos versiones distintas de la caída del ser o «Seinsverfall». En este sentido, es significativa su carta a Ernst Jünger, escrita en 1955, en la que, sabiendo que se dirige a un intelectual originariamente criptofascista como él mismo, puede entonar sin reservas de ninguna clase un responso filosófico sobre el triunfo planetario del nihilismo, detrás del cual no existe más que el luto por la desaparición del nacionalsocialismo y por la hegemonía mundial de los viejos enemigos los americanos y los rusos, aunque, por supuesto, el precavido Heidegger se cuide de pronunciar claramente estos nombres y recurra a los sobreentendidos ${ }^{24}$.

HELENO SAÑA

24. La carta a Ernst Jünger está incluida en «Zur Seinsfrage», «Gesammtausgabe», tomo 9, pp. 385-426, Francfort 1976. 